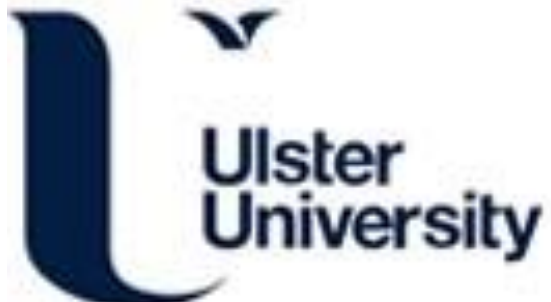

MICROCOMPUTER ANALYSIS OF JOINT VIBRATION

Kernohan, G., \& MOLLAN, RAB. (1982). MICROCOMPUTER ANALYSIS OF JOINT VIBRATION. Journal of Microcomputer Applications, 5(4), 287-296.

Link to publication record in Ulster University Research Portal

\section{Published in:}

Journal of Microcomputer Applications

Publication Status:

Published (in print/issue): 01/01/1982

\section{Document Version}

Publisher's PDF, also known as Version of record

\section{General rights}

Copyright for the publications made accessible via Ulster University's Research Portal is retained by the author(s) and / or other copyright owners and it is a condition of accessing these publications that users recognise and abide by the legal requirements associated with these rights.

\section{Take down policy}

The Research Portal is Ulster University's institutional repository that provides access to Ulster's research outputs. Every effort has been made to ensure that content in the Research Portal does not infringe any person's rights, or applicable UK laws. If you discover content in the Research Portal that you believe breaches copyright or violates any law, please contact pure-support@ulster.ac.uk. 


\title{
Microcomputer analysis of joint vibration
}

\author{
W. G. Kernohan and R. A. B. Mollan \\ Department of Orthopaedic Surgery, \\ The Queen's University of Belfast, \\ Musgrave Park Hospital, \\ Belfast BT9 7JB, UK
}

The diagnosis of human joint pathology is difficult and surgeons often resort to invasive methods of investigation. A technique of capturing joint vibration emission on a microcomputer is suggested as a likely aid to diagnosis, and some methods of analysis are described.

\section{Introduction}

Generally, the cause of a patient's suffering from painful joints can be found from the case history and by careful examination. An X-ray may reveal signs which confirm the diagnosis. However, taking the knee joint as an example, these methods are not sufficient for one in five cases. If some meniscal injury is suspected an air-arthrogram is often performed. This is an X-ray technique where air and a contrast medium are injected into the joint space, to outline the joint space and tears of the cartilage.

When the diagnosis is complicated a more invasive operation, such as Arthroscopy, is carried out. A small telescope is inserted into the joint space and allows direct viewing of the surfaces, usually requiring general anaesthetic. An exploratory operation (Arthrotomy) is only practical if no other test can explain the condition, and it also carries the risks of infection and anaesthesia.

Indeed none of these methods are totally objective and non-invasive.

\section{Background}

There have been several attempts to improve diagnosis of joint conditions by examining the vibration emission. Blodgett (1902) was first to apply a stethoscope to the knee and in his publication he describes how dots and dashes were used to record, and describe the types of sound he heard. Bircher (1913) went as far as to say that each type of injury had a distinctive sound emission, and Walters (1929) suggested that certain noises could be detected even before any other symptoms were apparent. Erb (1933) introduced the concept of a 'joint print' when he recorded sounds in the form of a graph. This allowed the sounds to be analysed in much greater detail.

By attaching sensitive microphones to the joint, some objectivity was introduced, and further graphical representations produced. Nevertheless diagnostic accuracy was so low that no valid clinical tool has yet been produced.

This development has continued with our examination of the microphone detection system. This has uncovered several shortcomings. Human joint emission was found to be 287

$0143-3792 / 82 / 040287+10 \$ 3.00 / 0$

(C) 1982 Academic Press Inc. (London) Limited 
outside the frequency range of microphones, and, because of coupling problems and background noise, microphones were considered inadequate (Mollan et al., 1982a).

We have shown accelerometers to be superior and that they overcome all of the problems associated with microphones (Mollan et al., 1982b).

\section{The new technique}

\subsection{Recording system}

Our present technique for recording knee-joint vibration is a three-accelerometer/ goniometer system with each accelerometer taped over the joint (Plate 1). The goniometer simultaneously records joint angle so that any episode of emission is referred to an angle. Signals from the transducers are amplified and then recorded on an instrumental tape recorder.

The recording is made as the patient flexes and extends his leg at approximately one complete cycle (flexion-extension-flexion) every $15 \mathrm{~s}$. This rate has been chosen arbitrarily to maximize grating and crepitus from the joint.

An attempt is made to control the speed of movement by providing the patient with an animated leg on the microcomputer. Figure 1 shows a single frame of this animation.

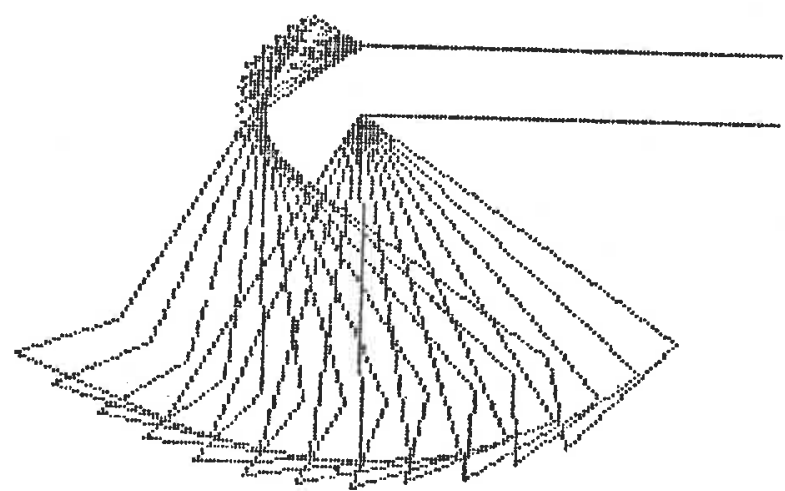

Figure 1. A single frame of the leg controller animation which the patient must imitate (one cycle $=15 \mathrm{~s}$ ).

The program (Figure 2) makes extensive use of built-in high-resolution graphics commands to draw the leg shapes. This application does not require isochronous programming since the major error in speed control will be in the patient's ability to imitate the animation. However, approximate calibration of the program was necessary so that known speeds could be used. To do this, the variable Loop-count was input directly and the corresponding time of movement measured for several different values. By assuming that a straight-line function related Loop-count to time in seconds then an expression relating the two could easily be found.

\subsection{The playback system and the IEEE-488 interface}

The tape recorder is played initially into an ink-jet recorder, providing a reference of the signals which are present in the joint cycle, albeit a compressed picture (Figure 3). 


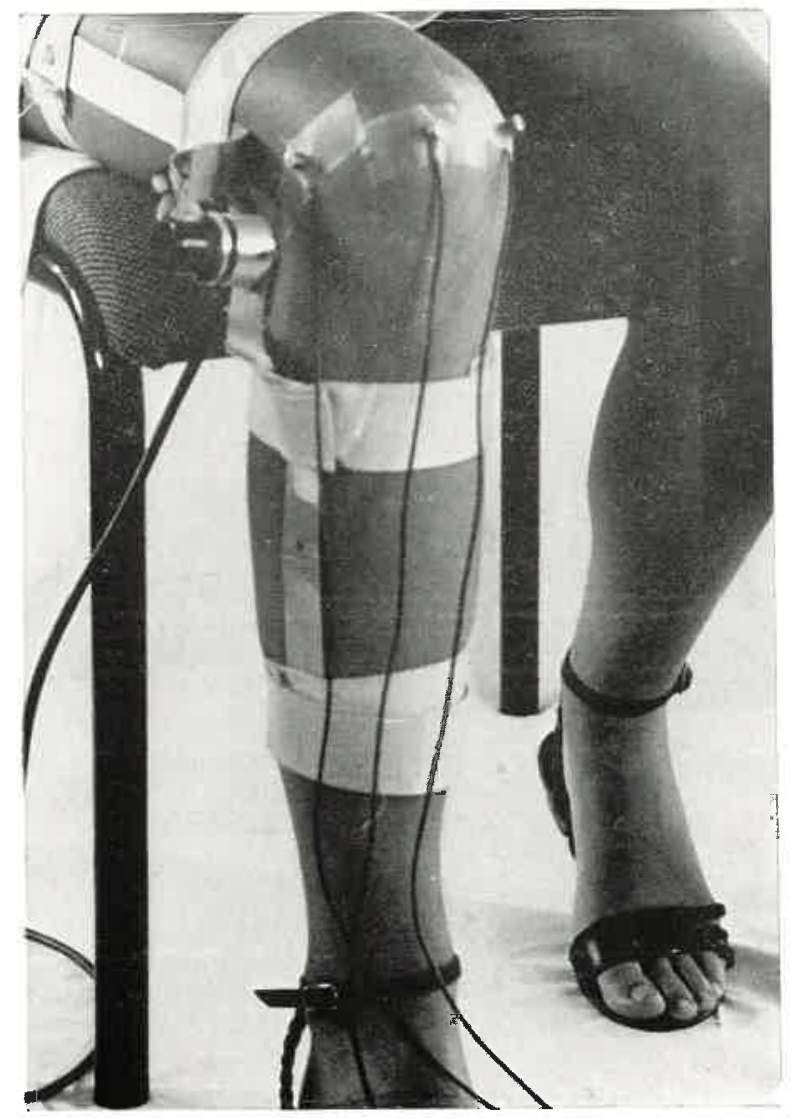

Plate 1. A patient's knee is under interrogation by three tiny accelerometers, taped on around the knee. The goniometer, which is fitted, consists of a potentiometer, hinged at the knee, having two shafts, belted to the leg, above and below the knee. 

Joint vibration analysis 289

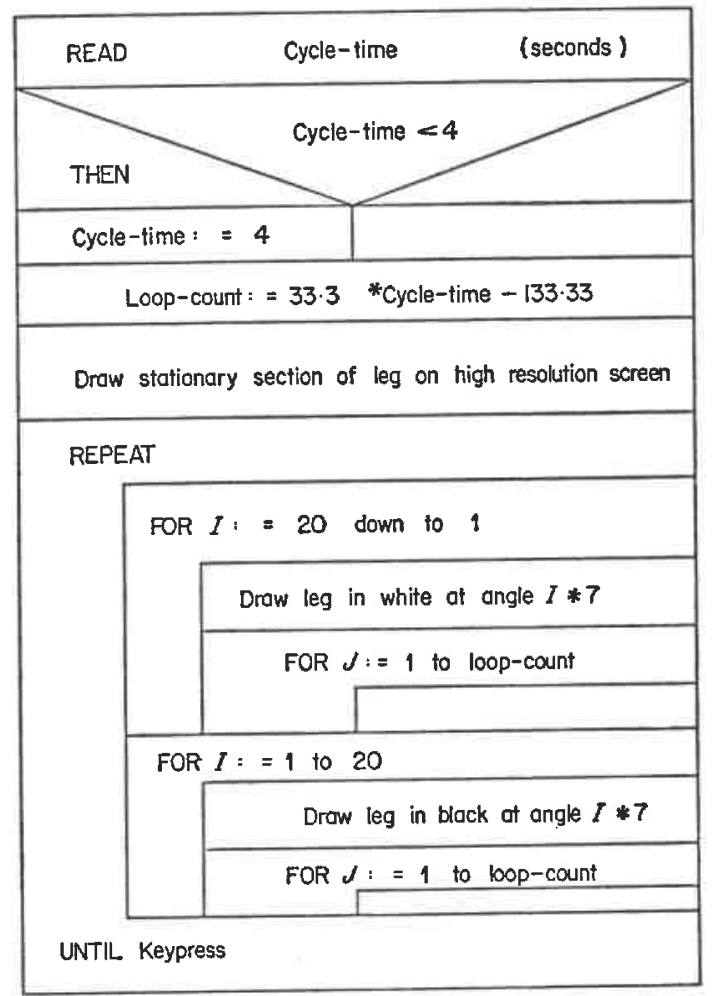

Figure 2. Structogram of the program to provide an animation in an attempt to control the speed of movement of a patient's leg, while a recording is made of its vibration emission.

Sections of interest can be identified from this reference and captured on a narrow band spectrum analyser (Bruel \& Kjaer 2031) for analysis.

One channel of the tape recorder is digitized by this machine and displayed. The trigger point, analogue/digital voltage range and sampling frequency are all push-key

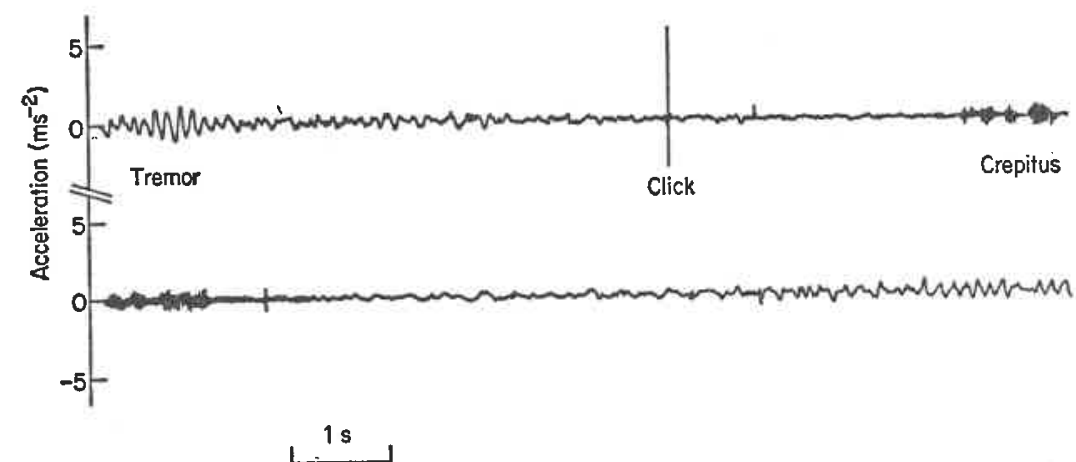

Figure 3. Joint print of the signal from a single accelerometer, showing the various vibration patterns in a single compressed picture. This recording was made as the patient moved his leg from extension to flexion (top trace) and back again (bottom trace). 


\section{W. G. Kernohan and R. A. B. Mollan}

selectable, and the Fourier transform of the captured window is available. However, the Bruel \& Kjaer machine has some disadvantages:

(a) Once captured, an interesting section may not be digitally stored.

(b) The scales of the machine are not in acceleration units.

(c) Apart from the frequency transform no other analysis technique is possible.

To overcome these limiting factors a link between this machine and an Apple 11 microprocessor has been established. This is the IEEE-488 'standardized' interface, consisting of connector cable and interface card in the Apple.

Control codes and data may be passed along the interface through one of the general input and output memory locations in the microcomputer. A program was required to arbitrate all transfers of data, making the Apple the 'controller' of the interface. Figure 4 shows the structogram for transfer of a time signal to and from the analyser. The

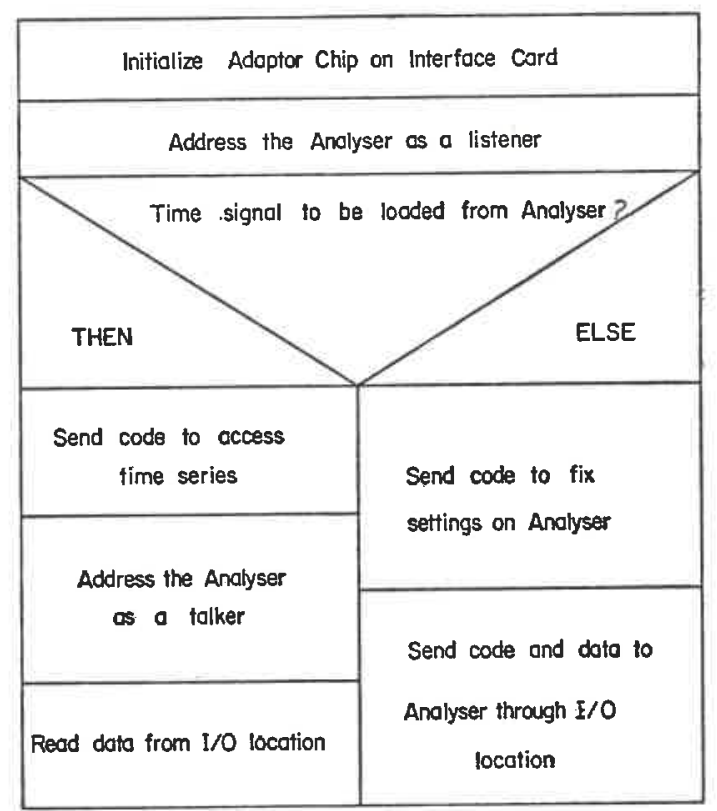

Figure 4. Structogram for transfer of a time signal between the spectrum analyser and the microcomputer.

adaptor chip, on the interface card, must first be initialized before data can be transferred. This initialization sets the adaptor chip to the state required for transfer routines. Now each machine on the IEEE interface has one address for data input: the listener address; and one for output: the talker address. In any data transfer, these addresses are first to be sent to the interface card. The sequence is

\section{$\langle$ Talker address〉 then \\ 〈Listener address〉}

Following this addressing sequence data can be sent or received through the same location in the microcomputer. Thus a protocol now exists for transfer of undefined data between the microcomputer and the analyser. To define the data it must be prefixed 
by some code. It is important to note that the codes used to define the data may only be sent with the analyser in listener mode and the addressing sequence must be repeated if data is to be received from the analyser. Alternatively, if data is to be sent to the analyser, the talker and listener addresses can remain the same throughout. Different prefix codes are used for the various transfer functions which are available. One will define the data required as output from the analyser. Another defines the data as pushkey settings to be fixed; such as sampling frequency and analogue-to-digital range. $\mathbf{A}$ third prefix is used to define the data for transfer to the analyser.

One advantage of this mechanism is that a complicated section of signal may be divided into sections, and a transform of each can be obtained. Alternatively, a 'clean-up' procedure in the Apple is used to remove unwanted low intensity siguals, thus increasing the transform accuracy.

\section{Analysis techniques}

\subsection{Exponential fit}

It is by reference to the complete joint print produced on the ink-jet recorder (Figure 3), that sections can be most easily captured and stored, for a more detailed study.

To produce a scaled waveform drawing, such as the patellar click (Figure 5), analyser and amplifier settings are required and these are saved when the data is stored on minidisc.

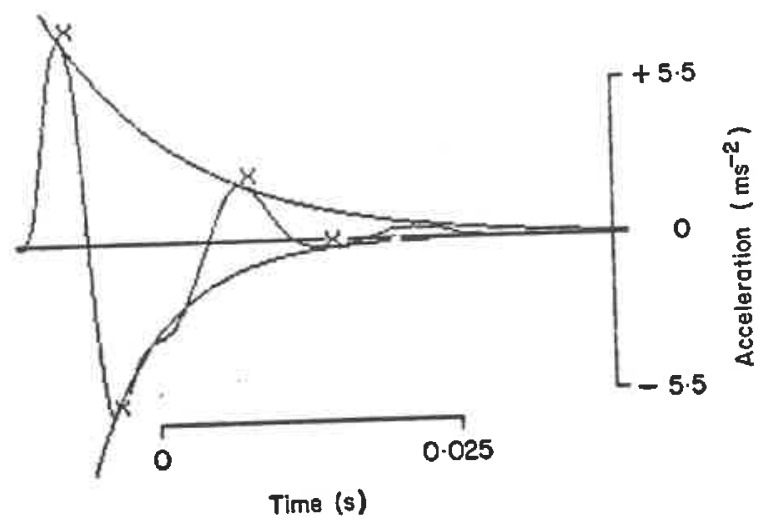

Figure 5. A calibrated drawing of a patellar click, showing exponential curve-fitting to the envelope of the decay.

When this file is reloaded the decay can be calculated by fitting an exponential to the curve. Much of the emission from joints has a characteristic decay and two points chosen to lie on the envelope of the decay are sufficient to define it:

Let the two points be $(X 1, Y 1)$ and $(X 2, Y 2)$. The decay of the pattern could be described by:

$$
y=A \exp (-a(x-b))
$$

where $A$ is the peak of the decay, $a$ is the decay constant and $b$ is the time delay.

$$
\frac{Y i}{A}=\exp (a X i+a b)_{\mathrm{i}=1,2}
$$




\section{W. G. Kernohan and R. A. B. Mollan}

Taking equations $(2) i=1 /(2) i=2$; then:

$$
a=\frac{\ln \left(\frac{Y 1}{Y 2}\right)}{X 2-X 1}
$$

and this will specify the rate of decay which will give a measure of the damping effect on the signal. Figure 6 shows the structogram of the procedure necessary to make this calculation. The points are visually chosen using a moving cursor, controlled by the micro-games paddles. An example of such an exponential fit is shown in Figure 5.

\subsection{Integration}

Digital integration of the acceleration data is also possible and some measure of the displacement can be obtained. This gives an estimate of how much the knee-cap moves, during a particular episode of emission.

The procedure is based on the trapezium rule for integration (Figure 7). Two adjacent sampled points, DATA $(I)$, Data $(I+1)$ and the zero line provide an area $A$, given by:

where

$$
A=\frac{1}{2}(\mathrm{DATA}(I)+\mathrm{DATA}(I+1)) * D T
$$

$$
D T=1 / \text { (sampling frequency) }
$$

The new (integrated) value will then be given by:

$$
\text { DATA }(I+1)=A+B
$$

where $B$ is the area calculated so far.

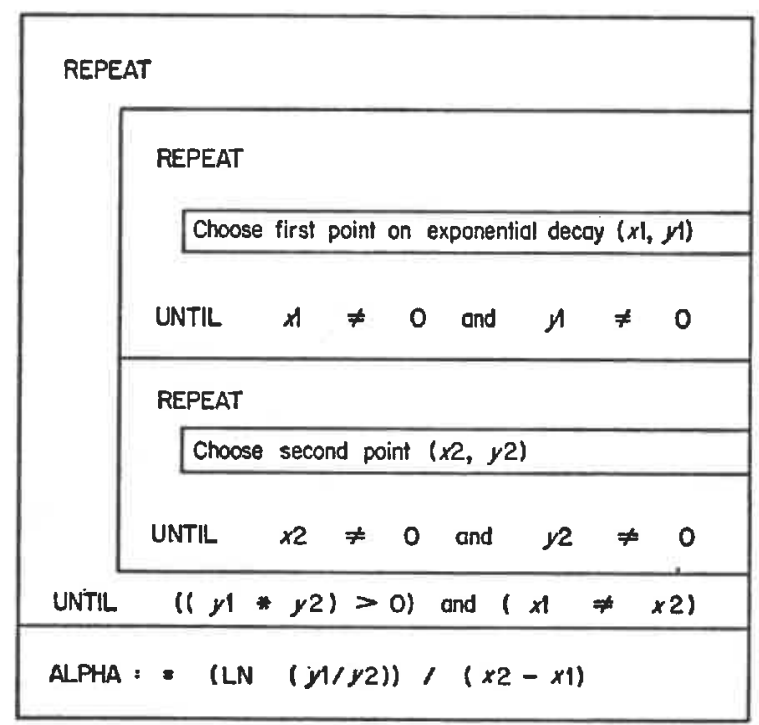

Figure 6. Structogram of the procedure which calculates the approximate decay constant of a joint vibration transient. 
DATA $(I+1)$ will, in fact, be required for the next incremental area, so (3) cannot be carried out until the next area has been evaluated.

Figure 8 shows the structogram of the program which is required for this calculation. On completion of the first loop, the indefinite integral results, so the baseline of the result

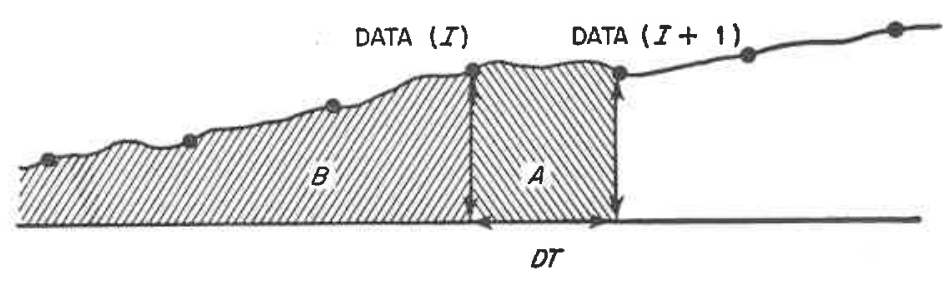

Figure 7. Signal integration by the Trapezium rule.

can be changed without introducing an error in the integration. However, if we assume that the transients tend to zero, before the last twenty values, in acceleration, velocity and displacement it is possible to obtain an accurate estimate of displacement for any given acceleration transient. The second loop, shown in Figure 8, enforces this zerovalue boundary condition at the twentieth value from the end.

This may be useful in clinical diagnosis, especially in cases where a joint vibration originates from a possible dislocation, where a significant movement is known to occur.

\begin{tabular}{|c|}
\hline HAF $:=0.5$ \\
SUM $1:=0$ \\
SUM $2:=0$ \\
\hline OT: $=1 /$ (sampling frequency) \\
FOR $I:=1$ 10 NUMB \\
\hline SUM $1:=$ HAF $*$ OT $(D A T A(I)+$ \\
DATA $(I+1)) * D T+\operatorname{SUM} 1 ;$ \\
DATA $(I):=\operatorname{SUM2;}$ \\
SUM $2:=\operatorname{SUM~} 1 ;$ \\
\hline CHANGE $:=$ DATA $($ NUMB -20$)$ \\
\hline FOR $I:=1$ to NUMB \\
\hline DATA $(I):=$ DATA $(I)-\operatorname{CHANGE}$ \\
\hline
\end{tabular}

Figure 8. Structogram of program for integration of an acceleration signal represented by DATA (I), $I=1 \ldots$ NUMB.

\subsection{Three accelerometers, two dimensions}

It is possible to get some idea of the source of any particular emission by using three accelerometers, sited around the joint. The three accelerometers define a plane through the joint and the source is identified as a point in this plane. If the accelerometers are 
carefully sited at the edge of the joint surface then this plane will coincide approximately with the joint surface.

The spectrum analyser, as a single-channel device, is not adequate for this application. Instead, a multichannel analogue-to-digital converter is used.

Our present work involves the programming of the Apple microcomputer to drive a 'Mountain Computer Inc.' converter. A variable-trigger, four-channel data acquisition routine has been written to store the data on disc in the same file format as before to allow drawings, decay-fitting and integration to be done.

Figure 9 shows the structogram for this program. After each value $V$ has been sampled, it is compared with the chosen trigger level $T$ and a count is kept of the number of values which are above that level.

If, after 256 samples, the number of overtrigger values exceeds two, then those samples are stored and a further 2816 samples taken, giving a total of $3 \mathrm{k}$ samples of acceleration data.

The subsequent two dimensional analysis may be based on time of arrival of transients at the three sites, or on their relative amplitudes, or on some combination thereof.

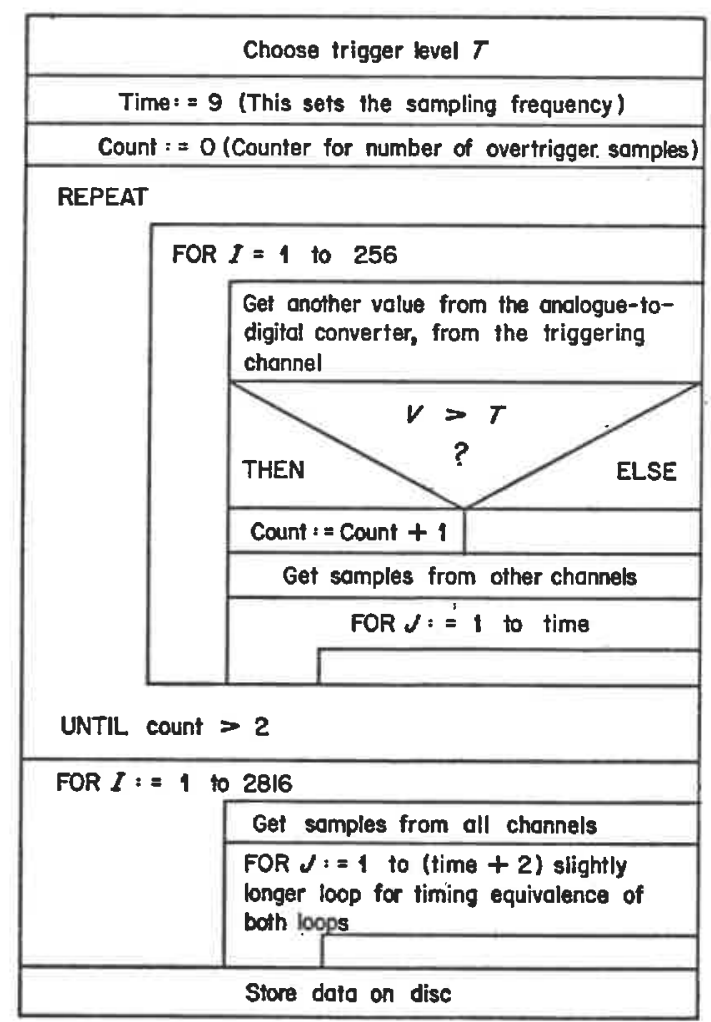

Figure 9. Structogram of the variable-trigger, four-channel data acquisition routine.

\section{Early results}

The microcomputer has been serving us for over one year, and our experiences with the system have been satisfactory. In a large clinical trial, using the accelerometers taped on 
to babies hips, it has been shown that the method is useful for the confirmation of congenital dislocation of the hip at birth, or diagnosing hips that may be at risk of developing a dislocation in the first months of life (Cowie, in preparation).

Various types of emission have been found in analysis of signals from accelerometers taped on to the patient's knee (see again Figure 3). One type is Tremor; a slow wave, of about $7-10 \mathrm{~Hz}$, found in patterns when the leg is approaching full extension. Tremor is probably caused by the muscle-nerve feedback control system as it attempts to keep the leg stationary at this position.

Another is Crepitus; a periodic, complex sinusoid, which we consider to be related to roughness of the joint surfaces. There is a peak in the frequency transform of crepitus at $120 \mathrm{~Hz}$, and, at peak vibration, the acceleration range is $\pm 0.8 \mathrm{~m} / \mathrm{s}^{2}$.

The Click is the loudest signal, reaching up to $10 \mathrm{~m} / \mathrm{s}^{2}$. It is also the shortest transient, lasting only $30 \mathrm{~ms}$, with a peak frequency of $60 \mathrm{~Hz}$. We find it generally occurs at the same joint position, and once in every joint cycle. In one patient we consistently found the click at $100^{\circ}$ of flexion, or within a few degrees of this, as the leg was moving towards the leg-straight position, at $0^{\circ}$. A typical decay constant for a patellar click is 0.03 . It can be associated with a displacement of the knee-cap of up to $0.3 \mathrm{~mm}$.

Tremor, crepitus and clicks have all been found in normal, pain-free joints but their parameters vary from one person to the next.

We are planning various experiments to see what affects the signals, such as excessive loading, or exercise.

We consider these signals to contain joint condition information and, by analysing them in various ways, we hope to extract this information to enhance clinical diagnosis. 


\section{W. G. Kernohan and R. A. B. Mollan}

\section{References}

Bircher, E. 1913. Sur Diagnose der Meniscusluxationen und des Meniscusabrusses. Zentralblatt für Chirurgie, 40, 1852.

Blodgett, W. E. 1902. Auscultation of the knee joint. Boston Medical and Surgical Journal, 146, 63-66.

Cowie, G. H. A new technique in diagnosis of congenital dislocation of the hip (in preparation).

Erb, K. H. 1933. Ưber die Moglichkeit der Registrierung Von Gelenkgeraushen. Deutsche Zeitschrift für Chirurgie, 241, 237-240.

Mollan, R. A. B., McCullagh, G. C. \& Wilson, R. I. 1982a. A critical appraisal of auscultation of human joints. Clinical Orthopaedics and Related Research (in press).

Mollan, R. A. B., McCullagh, G. C. \& Wilson, R. I. 1982b. Vibration emission: a new diagnostic technique. Clinical Orthopaedics and Related Research (in press).

Walters, C. F. 1929. The value of joint auscultation. Lancet, i, 920.

George Kernohan is a research assistant in the Department of Orthopaedic Surgery, Queen's University of Belfast. He gained BSc (Hons) combined Science (applied maths and physics) at the Ulster Polytechnic in 1980. Since then he has been involved in applications programming at Musgrave Park Hospital dealing mainly with the new technique of joint vibration analysis.

He is also a part-time lecturer in physical science and microelectronics at the Newtownabbey Technical College.

R. A. B. Mollan is Professor and Consultant in Orthopaedic Surgery at Queen's University, Royal Victoria Hospital and Musgrave Park Hospital, Belfast. He gained his FRCS Edinburgh in 1974 . He is the leader of a very active research team who are a combination of medics and scientists. He recently received The Robert Jones Gold Medal and The British Orthopaedic Association Prize as a result of his research work. 